\title{
Goldenhar syndrome
}

\author{
Síndrome de Goldenhar
}

João Maria Ferreira', Jéssica Gonzaga²

\begin{abstract}
The authors present a case of Goldenhar syndrome, with its characteristic features and variations. A male child of four years old at the Ophthalmology Service, Hospital São José The diagnosis was completed due to external and internal changes of the patient, after being evaluated by pediatrics, genetics, otolaryngology and ophthalmology. The oculoauriculovertebral spectrum (OAVS) known as Goldenhar Syndrome is a rare, complex and phenotypically variable condition, of still unknown origin is characterized by dermoid cysts epibulbar, auricular appendices and mandibular hypoplasia. We aim to case report, given the rarity of this syndrome and varieties of presentation spectrum, increase knowledge of the medical profession on this subject, to facilitate recognition and help conduct before future cases.
\end{abstract}

Keywords: Goldenhar syndrome/diagnosis; Dermoid cyst; Case reports

\section{RESUMO}

Os autores apresentam um caso de síndrome de Goldenhar, com seus aspectos característicos e variações, observando uma criança do sexo masculino de 4 anos de idade no Serviço de Oftalmologia do Hospital São José na cidade de Teresópolis (RJ). O diagnóstico foi concluído devido às alterações externas e internas do paciente após ter sido avaliado pela pediatria, genética, otorrinolaringologia e oftalmologia. O espectro óculo-aurículo-vertebral (EOAV) conhecida como Síndrome de Goldenhar é uma condição rara, complexa e fenotipicamente variável. De origem ainda desconhecida é caracterizada por cistos dermóides epibulbares, apêndices auriculares e hipoplasia mandibular. Objetivamos com este relato de caso, dada a raridade desta síndrome e variedades do espectro de apresentação, aumentar o conhecimento da classe médica sobre este assunto, para facilitar seu reconhecimento e auxiliar condutas perante casos futuros.

Descritores: Síndrome de Goldenhar/diagnóstico; Cisto dermóide; Relatos de casos

\footnotetext{
1 Medicine Department, Centro Universitário Serra dos Órgãos, Teresópolis, RJ, Brazil.

2 Graduation Course in Medicine, Centro Universitário Serra dos Órgãos, Teresópolis, RJ, Brazil.

Institution: Hospital São José - HSJ - Teresópolis (RJ), Brazil

The authors declare no conflicts of interests.

Received for publication 07/04/2015 - Accepted for publication 14/12/2015
} 


\section{INTRODUCTION}

$\mathbf{T}$ The oculo-auriculo-vertebral spectrum (OAVS) known as Goldenhar syndrome was described by Goldenhar in 1952 and completed by Gorlin in 1936.It is a syndrome with peculiarities that underlie symptoms from ear (especially microtia/ anotia and preauricularappendices), to face (hemifacial microsomia), eyes (epibulbar dermoid and microphthalmia) or column (vertebral changes) involvement.This is a rare syndrome with an estimated prevalence of 1:26,000 live births with a higher prevalence in males $(3: 2){ }^{(1)}$

In the literature we see that its etiology is characterized by involvement of the first branchial arches, and there are reported cases suggesting the existence of genetic factors, withrecessive autosomal and dominant autosomal pattern of inheritance. ${ }^{(2)}$

Several published studies have shown the presence of genetic abnormalities and pregnancy exposures as:exposure to thalidomide, retinoic acid and diabetes mellitus, mimicking his phenotype. . $^{(3,4)}$

We report here a case of Goldenhar Syndrome, a syndrome with few descriptions in the literature, bypassing its presentation, diagnosis and conduct on ophthalmic complaint

\section{Case Report}

A.A.S.R, male, 4 years old, brown, born in Teresópolis/RJ. On 01/14/2015 the mother searched the Ophthalmology service at Hospital São José stating that her son A.A.S.R. presented the diagnosis of Goldenhar Syndrome and developed "cysts in both eyes with discomfort and photophobia", with no additional complaints.

The mother reported in directed anamnesis that the diagnosis was given by the pediatrics, genetics and otolaryngology in the first year of her son's life.She also reported that the child underwent surgery 30 days before to treat a urethral fistula.According to the mother, there is no report of family cases; parents are healthy.The patient attends nursery.However, he does not have fluent speech and obeys poorly the commands. The mother reports having gone to other Ophthalmology services,with no indication for surgery, despite the complaints reported by the mother, such as:Lacrimation, hyperemia, secretion and constant itching.

During the exam, it was not possible to check the visual acuity, because the patient did not cooperate and could not identify the drawings presented.Regarding biomicroscopy, it was presentin both eyes, with the appearance of a high, whitish, vascularized tumor lesionwith hair follicles across its surface (Figures 1,2 and 3). Corneal ulcerations could be seen in the right eye through the trauma in the lashes of the upper eyelid.The diagnosis of dermoid cysts in both eyes was suggested.

The MRI of both orbits showed no continuity solution of the posterior wall of dermoid cysts with the corneal surface and the sclera.It only showed hypoplasia of the jaw (Figure 4) and evident dermoid cyst (Figure 5). The surgery for excision of the dermoid cyst was scheduled for 02/06/2015.

The surgical procedure was performed under general anesthesia, with total removal of the dermoid cysts until the corneal surface, where the epithelial layerwas removed.There was cauterization of the deeper vessels of the dermoid injuries and perilimbar region, without stiches, and the immediate postoperative period was uneventful (Figure 6).
In the appointment on 02/25/2015, the patient showed no corneal ulcerations, no complaints and regression of inflammatory signals. The postoperativemedication was discontinued, and only ocular lubricant (sodium hyaluronate eyedrops) was prescribed.

We taught the mother how to monitor the child, and asked her to return once a month for 6 months to evaluate the prognosis of the lesion.

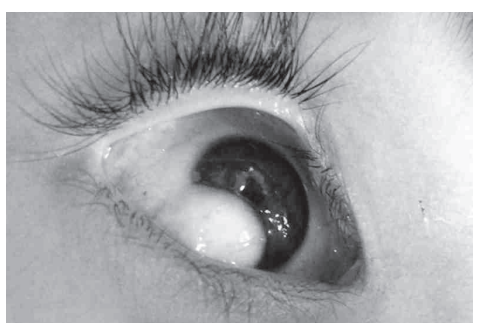

Figure 1: Dermoid cyst in the right eye.

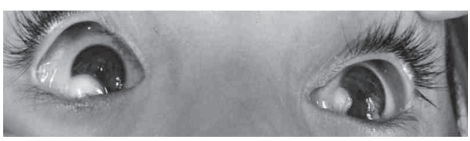

Figure 2. Bilateral dermoid cysts.

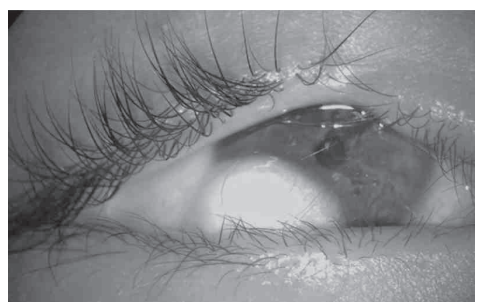

Figure 3. Dermoid cyst in the right eye; presence of hair in the cyst and corneal ulcer.

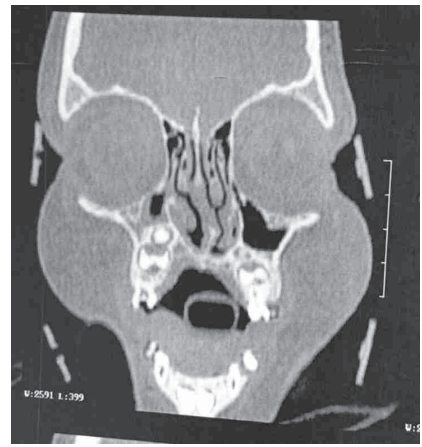

Figure 4. Magnetic resonance; mandibular hypoplasia.

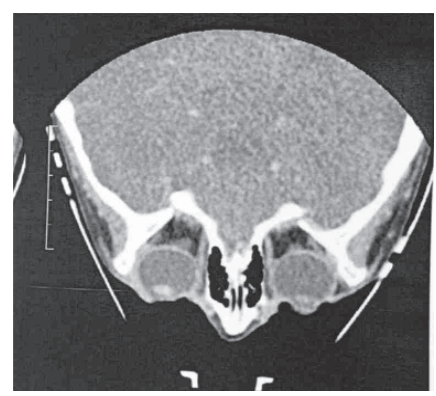

Figure 5. Magnetic resonance with dermoid cysts. 


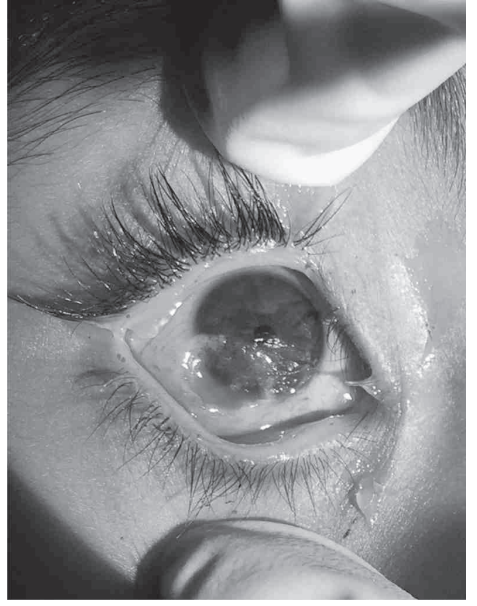

Figure 6. Immediate postoperative period.

\section{DisCUSSION}

Goldenhar Syndrome is part of the oculo-auriculo-vertebral spectrum (OAVS), being recognized as a syndrome by the presence of the same classic triad of eye, ear and vertebral changes.It is characterized primarily by auricularappendices, epibulbar dermoid cysts and hemifacial microsomia, besides heart, genitals, kidney, and lung disorders, including central nervous system and, in rare cases, lipomas of the corpus callosum are described ${ }^{1,3}$.

Goldenhar Syndrome was detected in 1845 by Von Arlt, and recognized as a clinical entity in 1952 by doctor Maurice Goldenhar, who described it in a child.It was also called "first arch syndrome" and "Gorlin syndrome". Currently, it is best known as oculo-auriculo-vertebral dysplasia., ${ }^{4,5}$

Of still unknown origin, it is known today that there is involvement of the first branchial arches ${ }^{6}$. Among the pathophysiological mechanisms that have been attributed to Goldenhar syndrome, there is the possibility of a reduced blood supply or focal hemorrhage in the developing region of the first and second branchial arches, occurred about 30-45 days of gestation, during the period of blastogenesis. These changes explain the disorders of the external ear, because the first branchial arch gives rise to the primordium of the anterior part of the auriculas, and the second branchial arch to the primordium of the posterior part of the ears?

Another hypothesis brings the idea that its etiology can be related to an abnormality of the migration of neural crest cells. Some studies suggest a recessive autosomal and an autosomal dominant pattern of inheritance ${ }^{8}$. In the literature there are descriptions of chromosomal abnormalities and gestational exposure to, for example, thalidomide, retinoic acid and diabetes mellitus, mimicking its fenotype ${ }^{9,10}$.

The diagnosis is based on clinical data:anamnesis, physical examination and the results of additional tests. The diagnosis of Goldenhar Syndrome can be performed during pregnancy by fetal ecography and genetic studies, and after birth by ecography and nuclear magnetic resonance ${ }^{11}$.

There are diagnostic criteria as the criteria used by Strämland et al. ${ }^{12}$, which is given when there are two or more features in the oro-cranium-facial, ocular, auricular and vertebral areas. There is also the criteria of Digilio et al.v, in which at least two of the following findings must be present:unilateral microtia, unilateral mandibular hypoplasia, epibulbardermoid cysts (unilateral or bilateral) or vertebral malformations. Unspecific symptoms were not reported ${ }^{13}$.

It is important to note that one of its characteristics is the extreme variability of expression of the individualsaffected.Some patients present a wide variety of anomalies.In others, only a discreet and simple anomaly is observed, as a pre-auricular appendix or a moderately dysplasic $\operatorname{ear}^{14}$. About $10 \%$ of patients have mental retardation. ${ }^{15}$

Among the structural changes found, we can highlight:macrostomia, open bite, cross bite, deep bite, high palate, cleft lip and palate, facial paralysis, micrognathia/retrognathia, unilateral hypoplasia of the mandibular branch and the condyle, geographic tongue, hypoplastic tongue, bifid tongue and uvula, agenesis of salivary gland appearance of fistulas, atrophy or hypoplasia of the masseter, temporalis and pterygoid, pharyngeal anomaly, tracheoesophageal fistula, aplasia or malformation of the external, middle and inner ear, preauricular dermal appendices, blind fistulae in the pre-draft region, unilateral microtia, and atresia of the external auditory meatus ${ }^{10,14}$.

Abnormalities in the eyes occur in about $50 \%$ of cases, and may present as small dermoid spots, epibulbar lipodermoids, coloboma (usually in the upper of the eyes), eyelid fissure, nasolacrimal duct obstruction, oftalmoplasia or Dnam syndrome, atrophied cataracts, enophthalmos, dermoid cysts, dry fistulas, microphthalmia and anophthalmia.The ocular anomalies most frequently found are dermoids and epibulbar lipodermoids ${ }^{13}$.

Auricular malformations can range from complete aplasia to external, middle and inner ear deformities, resulting in hearing loss.There are often preauricular fibromatosis appendices and cavities in the front part of the ear or in the line between it and the corner of the mouth.In auricular malformations, the ear canal can be completely absent, resulting in deafness (unilateral) in approximately $40 \%$ of cases $^{14,15}$.

The patient in the case described had dermoid cysts, auricular appendices (Figure 7), urethral fistula, as well as delay in development.

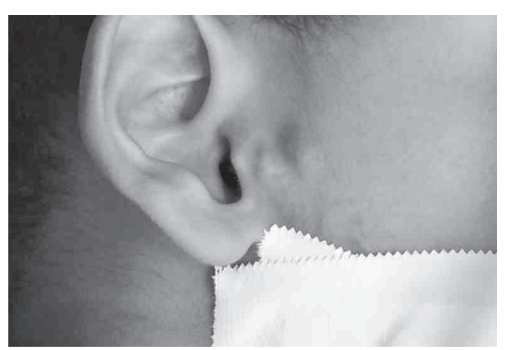

Figure 7. Auricular appendices.

A studied showed the prevalence of congenital heart defects (CHD) in patients with Goldenhar Syndrome, with a prevalence from 5 to $58 \%$.In this study, all patients with OAVS of the sample died before the end of the second year of life, due to complications directly related to their CHD.It is known that these defects are the leading cause of death of patients with OAVS, which typically occurs in the early years of life 9,11,12. $^{\text {. }}$

Treatment is made in each area in order to provide the best appropriate treatment, based on the literature and experience of the professionals involved.In the case reported, the dermoid cysts impair the patient's vision, besides the aesthetic damage, being of extreme importance the approach held in the Ophthalmology service. 
The subsequent preventive control in Goldenhar Syndrome should include assessments of sight, hearing, cervicalof the, kidney and heart function, and dentition. The feeding difficulties generally do not persist beyond the first year of life.Sometimes, the collaboration of speech therapists and dentists is necessary when there are malfunctions of the palate and dental anomalies. Therefore, this is a multidisciplinary approach $^{10,15}$.

Goldenhar Syndrome is still very rare and difficult to follow, as well as complex to treat.Their facial changes,in special micrognathia, are usually treated surgically.Ocular changes are treated with excision of dermoid or lipodermoid cysts.Deficits, especially in hearing, can also be treated with surgical procedures and audiologist follow-up.The variety of presentation spectrum of the disease, with varying degrees of involvement, is an aggravating factor to the diagnosis and monitoring of patients ${ }^{12,15}$.

\section{Conclusion}

As a rare syndrome, and usually diagnosed a priori by pediatricians and otolaryngologists, the syndrome often occurs without the expert in the field being initially sought, which can be observed in this specific case study.We observe, in this case, the need for surgical data showing that dermoid cysts cause an eyelid retraction leading to an entropion with ulcerated lesions of the cornea and subsequent significant loss of sight. The patient reported presented a postoperative period without any kind of complication, with healing of ulcerated cornealinjuries with no recurrences until the last follow-up.

In the case described, the lesion was the cause for great satisfaction and relief to parents who were eager for an incisive medical intervention that could provide improvement of the visual quality of her son.

We inferred from this study that publications related to rare incident diseases such as the one described in this report are important, considering that such descriptions provide greater assistance to professionals who may be dealing with this type of patient and thus can better treat them, facilitating their work and giving a faster and more accurate diagnosis.

The present study provides a more in-depth analysis of the syndrome, trying to offer specific elements about its etiology, diagnosis and surgical treatment.

\section{RefERENCES}

1. Cohen MM Jr, Rollick BR, Kaye CI. Oculoauriculovertebral spectrum: an updated critique. Cleft Palate J. 1989;26(4):276-86.

2. Morrison PJ, Mulholland HC, Craig BG, Nevin NC. Cardiovascular abnormalities in the oculo-auriculo-vertebral spectrum (Goldenhar syndrome). Am J Med Genet. 1992;44(4):425-8.
3. Castori M, Brancati F, Rinaldi R, Adami L, Mingarelli R, Grammatico $\mathrm{P}$, et al. Antenatal presentation of the oculo-auriculo-vertebral spectrum (OAVS). Am J Med Genet. 2006;140A(14): 1573-9.

4. Strömland K, Miller M, Sjögreen, Johansson M, Joelsson BM, Billstedt E, et al. Oculo-auriculo-vertebral spectrum: associated anomalies, functional deficits and possible developmental risk factors. Am J Med Genet. 2007;143A(12):1317-25.

5. Kumar A, Friedman JM, Taylor GP, Patterson MW. Pattern of cardiac malformation in oculoauriculovertebral spectrum. Am J Med Genet. 1993;46(4):423-6.

6. Digilio MC, Calzolari F, Capolino R, Toscano A, Sarkozy A, Zorzi $\mathrm{A}$, et al. Congenital heart defects in patients with oculo-auriculovertebral spectrum (Goldenhar syndrome). Am J Med Genet. 2008;146A(14):1815-9.

7. Rollnick BR, Kaye CI, Nagatoshi K, Hauck W, Martin AO. Oculo auriculovertebral dysplasia and variants: phenotypic characteristic of 294 patients. Am J Med Genet. 1987;26(2):361-75.

8. Tasse C, Böhringer S, Fischer S, Lüdecke HJ, Albrecht B, Horn D, et al. Oculo-auriculo-vertebral spectrum (OAVS): clinical evaluation and severity scoring of 53 patints and proposal for a new classification. Eur J Med Genet. 2005;48(4):397-411.

9. Friedman S, Saraclar M. The high frequency of congenital heart disease in oculo-auriculo-vertebral dysplasia (Goldenhar's syndrome). J Pediatr. 1974;85(6):873-4.

10. Greenwood RD, Rosenthal A, Sommer A, Wolff G, Craenen J. Cardiovascular malformations in oculoauriculovertebral dysplasia (Goldenhar syndrome). J Pediatr. 1974;85(6):816-8.

11. Touliatou V, Fryssira H, Mavrou A, Kanavakis E, Kitsiou-Tzeli S. Clinical manifestations in 17 Greek patients with Goldenhar syndrome. Genet Couns. 2006;17(3):359-70.

12. Lisbôa RC, Mendez HM, Paskulin GA. Síndrome de Goldenhar e variantes: relato de sete pacientes. Rev AMRIGS. 1987;31:265-9

13. Bustamante LN, Guerra IV, Iwahashi ER, Ebaid M. Síndrome de Goldenhar. Relato de cinco casos em associação com malformações cardíacas. Arq Bras Cardiol. 1989;53(5):287-90.

14. Verona LL, Damian NG, Pavarina LP, Ferreira CH, Melo DG. Monozygotic twins discordant for Goldenhar syndrome. J Pediatr. 2006;82(1):75-8.

15. Lima FT, Araújo CB, Sousa EC, Chiari BM. Alterações fonoaudiológicas presentes em um caso de síndrome de Goldenhar. Rev Soc Bras Fonoaudiol. 2007;12(2):141-5.

Corresponding author

João Maria Ferreira

R.Edmundo Bittencourt, № 70, - Várzea, Teresópolis, RJ, Brazil.

E-mail:clinoft@hotmail.com 